\title{
Research on Cruise Tourists Satisfaction Based on Web Text and IPA Analysis: A Case Study of Royal Caribbean Cruise
}

\author{
Zhang Gaoping ${ }^{1,}$ * Wang Sheduxiu ${ }^{2}$

\begin{abstract}
${ }^{1}$ School of economic management, Jiangsu University of science and technology, Zhenjiang, China 1
${ }^{2}$ School of economic management, Jiangsu University of science and technology, Zhenjiang, China 2

*Zhang Gaoping. Email: 1733903194@qq.com
\end{abstract}

\begin{abstract}
This paper takes Royal Caribbean cruise ship as the research object, and combines the analytic hierarchy process and content analysis, constructs the satisfaction index system of Royal Caribbean cruise ship from four aspects: cruise accommodation, cruise catering, cruise service and cruise entertainment. The paper uses Houyi Caijiqi to capture the comments of Royal Caribbean cruise ship on Ctrip tourism network, aiming at 24, 150 effective comments, word frequency analysis and IPA analysis were carried out to provide feasible suggestions for Royal Caribbean cruise ship to improve tourists' satisfaction.
\end{abstract}

Keywords: Online review, Satisfaction, IPA analysis

\section{INTRODUCTION}

Domestic and foreign scholars' research on cruise ships focuses on the market status of cruise tourism, economic value, marketing of cruise products and tourist behavior, etc. Xiaoting Huang[1] combined customer satisfaction theory and value theory to conduct an indepth analysis and discussion on the marketing strategy of cruise companies; Xing Xu et al. [2] established the statistical classification system of china's cruise industry, so that coastal cities can clarify their own position, develop together, and accelerate the development of the cruise industry; Yi Bowen et al. [3] tested the influencing factors of tourists' behavior under different cultural backgrounds by the structural equation model so as to put forward suggestions.

Research on the application of tourist satisfaction theories and models is relatively extensive. Mengyan $\mathrm{He}$ et al. [4] extracted high-frequency feature words related to tourist experience, and conducted social network analysis to understand the perceived experience attributes of Chinese cruise tourists; Chunyan Zhao et al. [5] used the text content analysis method to test the factors affecting the satisfaction of tourists traveling based on the characteristics of high-frequency words in online reviews, the semantic network and the emotions of tourists; Liu Zhicheng et al. [6] constructed a structural equation model of the influencing factors of tourist satisfaction to ecological scenic spots, and compared them by SPSS and Amos; Ye Shihao et al. [7] used the data collected through questionnaire surveys and used the ACSI model to conduct difference testing and IPA data analysis to obtain the factors that affect the satisfaction of visitors to the Creative Cultural Park.

Based on the above documents, this article will start from the perspective of cruise tourists, grab internet comment data through Houyi Caijiqi, take tourist satisfaction as the core, and use the IPA analysis model to establish a Royal Caribbean cruise tourist satisfaction model, which integrates qualitative methods to compare tourists satisfaction .On this basis, countermeasures and suggestions for improving the satisfaction of Royal Caribbean Cruises tourists are put forward.

\section{A MODEL OF INFLUENCING FACTORS OF ROYAL CARIBBEAN CRUISE TOURIST SATISFACTION BASED ON AHP}

\subsection{Index Selection Principle}

Index selection follows the principles of systematicness, typicality, conciseness, scientificity, operability, quantification and comprehensiveness. 


\subsection{Composition of Royal Caribbean Cruise Satisfaction Evaluation Indicators}

Table 1. Royal Caribbean Cruise Tourist Satisfaction Indicators

\begin{tabular}{|c|c|c|}
\hline Target Layer & Factor Layer & Index Layer \\
\hline \multirow{21}{*}{$\begin{array}{c}\text { Royal Caribbean } \\
\text { Cruise Tourist } \\
\text { Satisfaction }\end{array}$} & \multirow{5}{*}{ Cruise Accommodation } & Guest room design \\
\hline & & Security \\
\hline & & Degree of cleanliness \\
\hline & & Timeliness of room service \\
\hline & & Room price (included in the ticket) \\
\hline & \multirow{5}{*}{ Cruise Service } & Service etiquette standard \\
\hline & & Timeliness of service \\
\hline & & Additional charges for services \\
\hline & & The attitude of service \\
\hline & & The quality of service \\
\hline & \multirow{5}{*}{ Cruise Catering } & Dining environment \\
\hline & & Price of additional goods \\
\hline & & Food tastes \\
\hline & & Dining convenience \\
\hline & & Types of dishes \\
\hline & \multirow{6}{*}{ Cruise Entertainment } & The entertainment environment \\
\hline & & Activity characteristics \\
\hline & & Project diversity \\
\hline & & Price for additional items \\
\hline & & The quality of service \\
\hline & & Schedule \\
\hline
\end{tabular}

According to the analytic hierarchy process, the paper proposes the following index system of China Cruise tourists satisfaction.

The first level: "cruise tourists satisfaction of the Royal Caribbean" is the overall evaluation index, which is the target level;

The second layer: it is divided into four factors: the satisfaction of tourists to cruise catering, accommodation, shopping and entertainment of cruise;

The third layer: combined with the characteristics of cruise tourism, the second level index is further divided into indicator level, namely, the specific problems of the evaluation index system of tourists satisfaction in online comments, and the factors such as cruise catering, cruise accommodation, cruise shopping and cruise entertainment are refined.

\subsubsection{Cruise Accommodation}

Cruise accommodation is an indispensable part of cruise tourism. Tourists pay more attention to the design, service, health and price of cruise rooms. The interior cabin is economical and warm in layout, but it is not convenient to see the scenery without external windows or balcony; the seascape room is well arranged and can enjoy the external scenery with high cost-effective; the suite is equipped with complete facilities, large space and enjoys the highest value. The cruise travel is mostly family-based, tourists pay attention to the personal safety of children and the elderly, and in addition, there are dense personnel. Once the disaster occurs, it is difficult to evacuate people, and the safety of accommodation can not be ignored. 


\subsubsection{Cruise Service}

Many online comments mentioned cruise service, including whether the service is timely, enthusiastic and thoughtful, whether the extra charge is charged, if the service makes tourists feel at home, the overall score of tourists' satisfaction will be higher

\subsubsection{Cruise Catering}

There are free restaurants and charging restaurants on the cruise line, which provide diversified catering services. Tourists pay attention to the types of catering, catering environment, diversified catering tastes, and the free snacks such as cake, pizza and coffee attract tourists a lot.

\subsubsection{Cruise Entertainment}

Cruise is a large amusement park, including supermarkets, bars, performing stage, swimming pool, gym, golf course, and so on. There are many kinds of entertainment programs on the cruise ship, which are wonderful. Tourists hope to have rich leisure activities in their leisure time, such as enjoying literary performances and swimming.

In summary, the evaluation index system of cruise satisfaction of Royal Caribbean is established. (see Table $1)$.

\section{ANALYSIS OF ROYAL CARIBBEAN CRUISE TOURIST SATISFACTION BY IPA}

\subsection{The Source of Data}

Ctrip is the largest online travel operator (OTA) in China, with the earliest opening of its website and the largest number of customer visits. In terms of data access channels, Ctrip as the source of cruise review website. From Ctrip, we selected the first voyage or refurbished cruise ships of Royal Caribbean International from 2014 to 2019 with more than 40 reviews, among which 6 cruise ships met the requirements, such as Ocean Symphony, Ocean Harmony, Ocean Voyager, Ocean Spectra, Ocean Zara and Quantum of the Seas (see Table 2).

\subsection{Sample Pretreatment}

Houyi Caijiqi was used to collect the review data of Royal Caribbean cruise ship on Ctrip, and the collected data was exported into Excel format. Excel was used to delete duplicate data, and 24,150 comments with characters greater than or equal to 30 were selected as the research data according to the comment content.

\subsection{Word Frequency Analysis}

It analyzes the overall word frequency of comments, focusing on tourists' experience of Royal Caribbean cruise ships, and useless words were deleted, such as cruise, of, sea, very, due to, because, and, and on board, etc., and 50 high-frequency words were selected according to the indicators constructed above. From the analysis of word frequency, it can be seen that tourists' satisfaction with cruise mainly comes from four aspects: cruise service, cruise catering, cruise entertainment and cruise accommodation. See Table 2 for specific word frequency.

Table 2. Word Frequency Summary

\begin{tabular}{|c|c|c|}
\hline Order Number & Word & Frequency \\
\hline 1 & Service & 1,200 \\
\hline 2 & Restaurant & 914 \\
\hline 3 & Pretty good & 784 \\
\hline 4 & Food & 493 \\
\hline 5 & Room & 450 \\
\hline 6 & Facility & 403 \\
\hline 7 & Buffet & 343 \\
\hline 8 & Satisfaction & 319 \\
\hline 9 & For free & 273 \\
\hline 10 & Abundant & 270 \\
\hline 11 & Entertainment & 268 \\
\hline 12 & Waiter & 249 \\
\hline 13 & Performance & 240 \\
\hline 14 & Common & 211 \\
\hline 15 & Journey & 203 \\
\hline 16 & Neat & 171 \\
\hline 17 & Charge & 152 \\
\hline 18 & Wonderful & 143 \\
\hline 19 & Guest room & 130 \\
\hline 20 & Amusement & 127 \\
\hline 21 & Taste & 126 \\
\hline 22 & Comfort & 113 \\
\hline 23 & Price & 90 \\
\hline 24 & Convenience & 89 \\
\hline 25 & Western food & 86 \\
\hline 26 & Suite & 78 \\
\hline 27 & Service attitude & 65 \\
\hline 28 & Environment & 65 \\
\hline 29 & Pleasant & 60 \\
\hline
\end{tabular}




\begin{tabular}{|c|c|c|}
\hline 30 & Tidy & 59 \\
\hline 31 & Hygiene & 56 \\
\hline 32 & Fruit & 46 \\
\hline 33 & Communication & 44 \\
\hline 34 & Cheap & 42 \\
\hline 35 & Delicacy & 38 \\
\hline 36 & Relaxation & 38 \\
\hline 37 & Crowd & 35 \\
\hline 38 & Grocery & 34 \\
\hline 39 & Friendly & 32 \\
\hline 40 & Intimacy & 32 \\
\hline 41 & Game & 30 \\
\hline 42 & Quality & 29 \\
\hline 43 & Memorable & 29 \\
\hline 44 & Service charge & 29 \\
\hline 45 & Friendly atmosphere & 27 \\
\hline 46 & Patience & 26 \\
\hline 47 & Good-looking & 20 \\
\hline 48 & Magic & 20 \\
\hline 49 & Spacious & 18 \\
\hline 50 & Unpalatable & 17 \\
\hline
\end{tabular}

\subsection{Satisfaction Analysis}

IPA analysis method was used to build the analysis model, for cruise catering service, cruise, cruise to play, cruise accommodation satisfaction analysis, four factors layer by tourists to score each item of factor layer of network, the average factor layer are calculated article number (see Table 3), use of user comments on times said in a proportion of the total number of comments on the dimension tourist satisfaction evaluation of the weight, namely to evaluate satisfaction degree of the importance of the evaluation system as the degree of satisfaction; Meanwhile, the average score of each factor layer was adjusted and taken as the importance (see Table 4). Through data analysis, the average value of importance is 0.25 , and the average value of satisfaction is 3.87 . With the vertical intersection point of importance and satisfaction as the origin, satisfaction as the horizontal axis and importance as the vertical axis, SPSS software was used to establish a two-dimensional four-quadrant grid diagram (as shown in Figure 1).
Table 3. The Average Value

\begin{tabular}{|c|c|c|}
\hline Project & $\begin{array}{c}\text { Average } \\
\text { Score }\end{array}$ & $\begin{array}{c}\text { Average } \\
\text { number }\end{array}$ \\
\hline Cruise Catering & 4.03 & 461 \\
\hline Cruise Accommodation & 3.82 & 84 \\
\hline Cruise Entertainment & 3.77 & 151 \\
\hline Cruise Service & 3.86 & 95 \\
\hline
\end{tabular}

Table 4. Importance and Satisfaction

\begin{tabular}{|c|c|c|}
\hline Project & Importance & Satisfaction \\
\hline Cruise Catering & 0.58 & 4.03 \\
\hline Cruise Accommodation & 0.11 & 3.82 \\
\hline Cruise Entertainment & 0.19 & 3.77 \\
\hline Cruise Service & 0.12 & 3.86 \\
\hline Overall Average & 0.25 & 3.87 \\
\hline
\end{tabular}

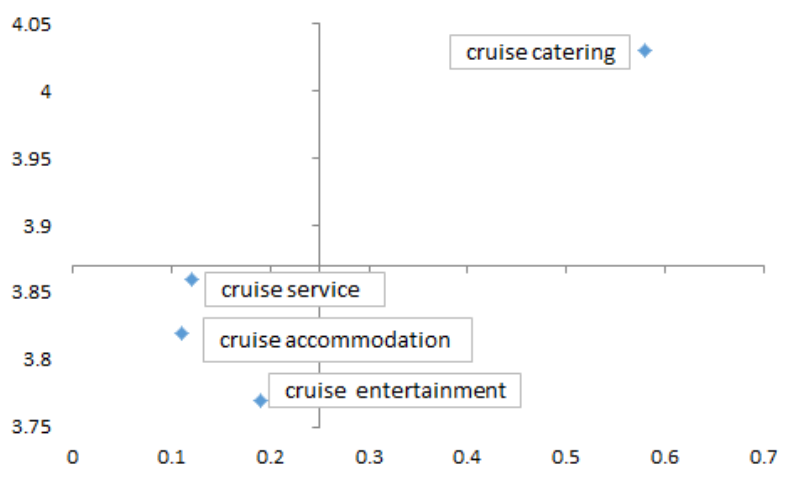

Figure1. Two-dimensional Four-quadrant Grid Diagram

\section{THE STRATEGY OF IMPROVING OF THE SATISFACTION OF ROYAL CARIBBEAN CRUISES}

According to the satisfaction analysis model of Royal Caribbean proposed above, the improvement strategy is proposed to solve the problems.

\subsection{Cruise Catering}

Before the design of cruise catering, analysis is conducted on the eating habits and culture of cruise tourists, as well as the age and region of tourists, so as to fully understand the dietary characteristics of tourists. We should strive to diversify the types of catering. For example, considering that is easy to digest and chew for the elderly, while the young like to try new things, and provide a variety of creative dishes for the young. Most importantly, the freshness, temperature and taste of dishes should be controlled as much as possible, so as to improve the quality of dishes and ensure the food quality of tourists. 


\subsection{Cruise Accommodation}

Room service, room comfort and room hygiene have an important impact on the satisfaction of tourists. The room decoration should avoid too many hotel elements, increase household atmosphere, increase the comfort of the bed, and configuration of basic family living supplies, make the visitors experience the convenience of occupancy, feel warm and comfortable. In addition, cruise companies should improve the service quality of guest rooms in such details as cleaning, fast food delivery and timely door opening.

\subsection{Cruise Entertainment}

Cruise experience, for most tourists, is to experience a variety of entertainment facilities on the ship. The richness of entertainment items, the characteristics of entertainment activities and the degree of participation in entertainment activities all have an important impact on the satisfaction of tourists. According to the tourist demands, cruise in setting entertainment activities is to consider the needs of different ages, have entertainment for young people.

In addition, entertainment programs should take into account all tourists as much as possible, enrich the content and variety of the programs, and incorporate a certain proportion of Chinese classical programs, such as comedy and storytelling, to meet the needs of Chinese elderly people who are slow to accept new things.

\subsection{Cruise Service}

Cruise Tours are mostly accompanied trips or family trips. The elderly and children account for a certain proportion, and the service work is relatively complicated, such as the elderly asking for directions. Cruise companies should improve the overall quality of service personnel, organize regular training, standardize service terms, and correct service attitude.

\section{CONCLUSION}

With royal Caribbean cruise lines as the research object, this paper combined with the relevant theoretical research, to build an index system of the satisfaction degree of the royal Caribbean cruise lines, and online comments for the royal Caribbean cruise lines has carried on the word frequency analysis and IPA analysis, found the royal Caribbean cruise lines in cruise catering, well in cruise to play, cruise service and cruise accommodation should be further perfect, and Suggestions are put forward according to the royal Caribbean cruise lines satisfaction.

\section{REFERENCES}

[1] Xiaoting Huang, Cruise Tourism Marketing Strategy Based on the Customer Satisfaction, Logistics Sci-Tech,36(03),2013,pp.127-129.

[2] Xing Xu, Tianhang Gao, Yihua Shen, Construction of the Classification System of China's Cruise Industry, China Transportation Review,42(12),2020,pp.36-43.

[3] Bowen Yi, Da Shi, Acculturation and Cultural Identity: A Study of the Behaviors of Chinese Cruise Tourists, Journal of Yunnan Minzu University(Social Sciences),38(02),2021,pp.19-29.

[4] Mengyan He, Yanqing ZHANG, Mingyu WU,Study on Experience of Cruise Tourist based on Web Text Analysis, Tourism Forum,10(06),2017,pp.51-62.

[5] Chunyan Zhao, Meiai Chen, Analysis of Influencing Factors of Tourist Satisfaction Based on Web Text Analysis, Statistics \& Decision,35(13),2019,pp.115118.

[6] Zhicheng Liu, Yiling Qian, Study on Tourist Satisfaction of Wuling Source Ecological Tourism Scenic Area Based on SEM Model, Social Sciences in Hunan,(03),2019,pp.121-127.

[7] Shihao Ye, Zhou Li, Research on Influencing Factors of Tourist Satisfaction in Creative and Culture Parks Based on IPA —-A Case of Creative and Culture Parks in Shenzhen City, Resource Development \& Market,36(07),2020, pp.775-881. 